after imatinib was reported to date; yet, the case differs with our case in that the eruption was well-controlled with a dose reduction to $300 \mathrm{mg}$ per day ${ }^{4}$. Ugurel et al. ${ }^{5}$ reported that imatinib acts as a dose dependent inducer of the development of LDE and may show mild reactivity to low or intermediate dose (200 to $600 \mathrm{mg} /$ day). However, in this case, the patient suffered from extensive drug eruption in spite of the low dose of $200 \mathrm{mg}$ per day. We present here LDE after imatinib treatment of $400 \mathrm{mg}$ per day to a low dose of $200 \mathrm{mg}$ per day. This case presented that a low dose of imatinib does not always prevent LDE and can induce severe eruption in some patients. We suggest clinicians to keep in mind that all patients taking imatinib mesylate have the possibility of extensive LDE even in a low dose and therefore should carry a close observation.

\section{REFERENCES}

1. Kawakami T, Kawanabe T, Soma Y. Cutaneous lichenoid eruption caused by imatinib mesylate in a Japanese patient with chronic myeloid leukaemia. Acta Derm Venereol 2009; 89:325-326.

2. Amitay-Laish I, Stemmer SM, Lacouture ME. Adverse cutaneous reactions secondary to tyrosine kinase inhibitors including imatinib mesylate, nilotinib, and dasatinib. Dermatol Ther 2011;24:386-395.

3. Dalmau J, Peramiquel L, Puig L, Fernández-Figueras MT, Roé E, Alomar A. Imatinib-associated lichenoid eruption: acitretin treatment allows maintained antineoplastic effect. Br J Dermatol 2006;154:1213-1216.

4. Yang JH, Shin JW, Kim HD, Park YL, Lee SY, Whang KU. Imatinib mesylate (Gleevec(TM))-induced lichenoid drug eruption improved by tentative dose-reduction and topical steroid. Korean J Dermatol 2011;49:155-158.

5. Ugurel S, Hildenbrand R, Dippel E, Hochhaus A, Schadendorf D. Dose-dependent severe cutaneous reactions to imatinib. $\mathrm{Br}$ J Cancer 2003;88:1157-1159.

\title{
Minor Salivary Gland Sialolithiasis of the Upper Lip
}

\author{
Dong-Woo Suh, Eun-Ju Lee, Bark-Lynn Lew, Woo-Young Sim \\ Department of Dermatology, Kyung Hee University School of Medicine, Seoul, Korea
}

\section{Dear Editor:}

Sialolithiasis is a common disease of the salivary glands. Most calculi occur in the major salivary glands such as the submandibular glands ( $80 \%$ to $92 \%)$ and parotid glands $(16 \%$ to $19 \%)$, while minor salivary glands are rarely affected $(2 \%)^{1}$. Minor salivary gland sialolithiasis is characterized by a small, solitary submucosal nodule, which is hard and in some cases can be movable in the surrounding tissue ${ }^{2}$. Since it is rare and its clinical features are not always typical, clinical misdiagnosis is possible ${ }^{3}$. Most otolaryngologists and dentists are relatively familiar with sialolithiasis, but many dermatologists are not. In order to heighten the awareness of this disease and to facilitate diagnosis, we report a case of minor salivary gland sialolithiasis that was initially misdiagnosed clinically.

A 56-year-old man presented with a six-year history of an asymptomatic solitary submucosal nodule on the upper lip. He reported no history of trauma to the lip. Physical

Received November 22, 2012, Accepted for publication December 5, 2012

Corresponding author: Bark-Lynn Lew, Department of Dermatology, Kyung Hee University Hospital at Gangdong, 892 Dongnam-ro, Gangdong-gu, Seoul 134-727, Korea. Tel: 82-2-440-7329, Fax: 82-2-440- 7336, E-mail: bellotte@hanmail.net

This is an Open Access article distributed under the terms of the Creative Commons Attribution Non-Commercial License (http:// creativecommons.org/licenses/by-nc/3.0) which permits unrestricted non-commercial use, distribution, and reproduction in any medium, provided the original work is properly cited. 
examination revealed a small $(0.4 \times 0.4 \mathrm{~cm})$, firm, movable, well-defined submucosal nodule on the inner side of the upper lip (Fig. 1). We presumed the lesion was a mucocele and performed excisional biopsy. Histopathologic examination revealed heterogeneous lamellated calculi within the lumen of a dilated minor salivary duct. The calculi had a relatively homogenous core with alternating basophilic and eosinophilic bands at the periphery (Fig. 2A). The excretory ductal epithelium had undergone squamous metaplasia (Fig. 2B). These pathological features were consistent with the diagnosis of minor salivary gland sialolithiasis ${ }^{3,4}$.

A sialolith of the minor salivary glands is commonly described as a solitary, firm, asymptomatic, mobile nodule. It is most likely to develop near the upper lip and buccal mucosa that are susceptible to masticatory trauma ${ }^{4}$. Its clinical characteristics can resemble those of other lesions,

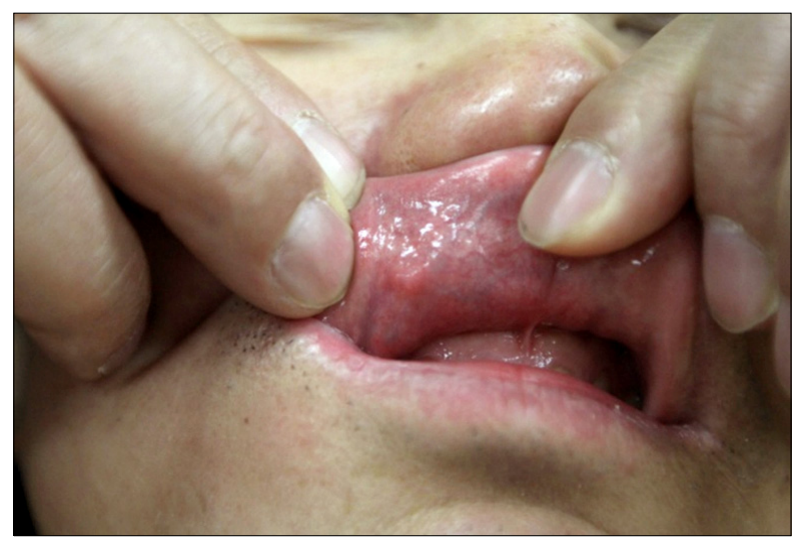

Fig. 1. A $0.4 \times 0.4 \mathrm{~cm}$ sized, firm, mobile, asymptomatic nodule on the inner side of the upper lip.

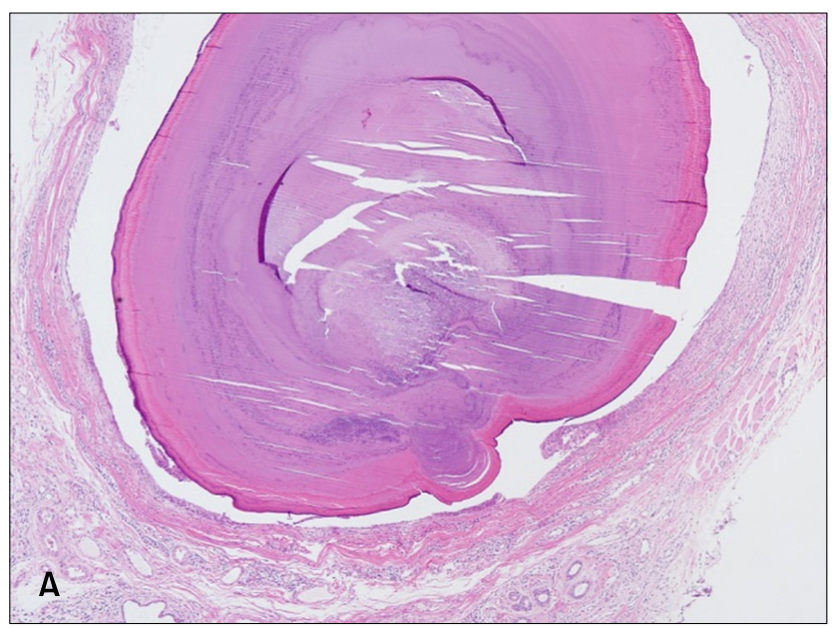

resulting in frequent misdiagnosis. Anneroth et al. observed the correct diagnosis was made in only $20 \%$ of patients $^{2}$. The differential diagnosis includes mucocele, foreign body, benign salivary neoplasm, and calcinosis cutis. A mucocele is clinically similar to minor salivary gland sialolithiasis. However, it can be readily diagnosed because of its cyst-like appearance lined by granulation tissues. A foreign body is difficult to diagnose unless imaged by radiography. It can only be confirmed after excision and microscopic examination. A benign minor salivary neoplasm tends to be an indolent, painless, firm, nodule, and the most frequent location is the same as minor salivary gland sialolithiasis. Microscopic examination is required to determine the exact histologic nature of the tumor. Several case reports have described calcinosis cutis of the lip, and this condition is difficult to differentiate from minor salivary gland sialolithiasis ${ }^{5}$. However, it reveals relatively homogeneous calcium deposits surrounded by epithelial-like cells, rather than heterogeneous lamellated calculi.

Sialolithiasis of the minor salivary glands is frequently misdiagnosed, mostly because its frequency, signs, and symptoms are relatively unknown, especially to dermatologists. We should be aware of this disease and consider it as a possible diagnosis when swelling of the oral mucosal tissues is observed in a patient.

\section{REFERENCES}

1. Ben Lagha N, Alantar A, Samson J, Chapireau D, Maman L. Lithiasis of minor salivary glands: current data. Oral Surg Oral Med Oral Pathol Oral Radiol Endod 2005;100:345-348.

2. Anneroth G, Hansen LS. Minor salivary gland calculi. A clinical and histopathological study of 49 cases. Int J Oral

Fig. 2. (A) Heterogeneous lamellated calculi were found within the lumen of a dilated minor salivary duct $(H \& E, \times 40)$. (B) Squamous metaplasia of the excretory ductal epithelium and exfoliated epithelium were observed in the minor salivary glands (H\&E, $\times 200)$. 
Surg 1983;12:80-89.

3. Favia G, Capodiferro S, Turco M, Cortelazzi R. Lithiasis of minor salivary glands of the upper lip. Clinico-pathological report of a case with unusual presentation. Minerva Stomatol 2004;53:179-183.

4. Lee LT, Wong YK. Pathogenesis and diverse histologic findings of sialolithiasis in minor salivary glands. J Oral Maxillofac Surg 2010;68:465-470.

5. Antoniades DZ, Markopoulos AK. Mucosal calcified nodule of the lower lip: report of a case and review of the literature. Int J Dermatol 2006;45:868-869.

\title{
Cetuximab Related Eyelash Elongations for Patients with Metastatic Rectum Carcinoma: Metabolic Complete Response
}

\author{
Yüksel Ürün, Güngör Utkan \\ Department of Medical Oncology, Ankara University School of Medicine, Ankara, Turkey
}

\section{Dear Editor:}

Colorectal cancer (CRC) is the second most common cause of cancer related death for developed countries.

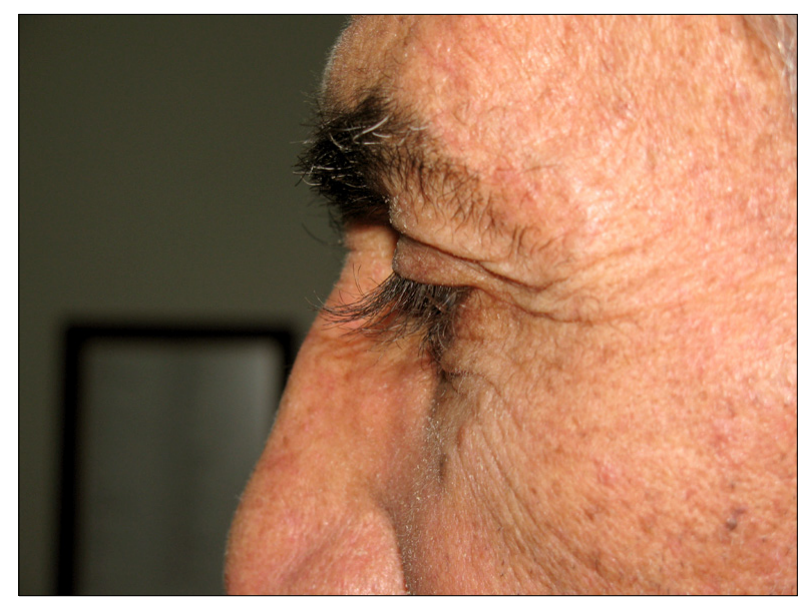

Fig. 1. Eyelash elongation after cetuximab treatment (published with permission of patient).
Over the past decades, significant improvements have been achieved on the pathogenesis of CRC and new therapeutic options are available today. However, it is not

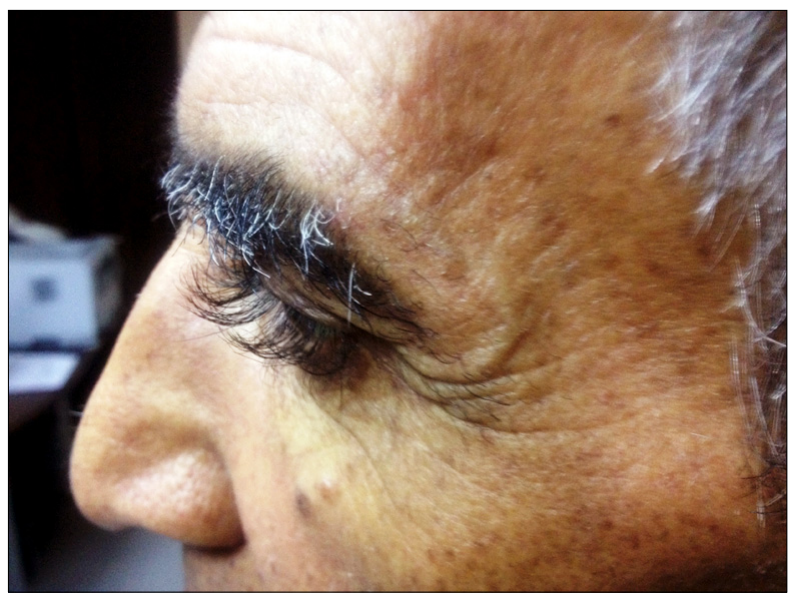

Fig. 2. Patient's second photograph after reintroduction of cetuximab (published with permission of patient).

Received August 29, 2011, Revised November 29, 2012, Accepted for publication December 7, 2012

Corresponding author: Yüksel Ürün, Department of Medical Oncology, Ankara University School of Medicine, Ankara 06590, Turkey. Tel: 90312-595-7112, Fax: 90-312-319-2283, E-mail: yukselurun@gmail.com

This is an Open Access article distributed under the terms of the Creative Commons Attribution Non-Commercial License (http:// creativecommons.org/licenses/by-nc/3.0) which permits unrestricted non-commercial use, distribution, and reproduction in any medium, provided the original work is properly cited. 